\title{
Correction to: Different impacts of metabolic profiles on future risk of cardiovascular disease between diabetes with and without established cardiovascular disease: the Japan diabetes complication and its prevention prospective study 7 (JDCP study 7)
}

\author{
Mitsuyoshi Takahara ${ }^{1} \cdot$ Naoto Katakami $^{2}$ (D) $\cdot$ Yasuaki Hayashino $^{3} \cdot$ Rimei Nishimura $^{4} \cdot$ Hiroaki Suzuki $^{5}$. \\ Hitoshi Shimano ${ }^{5} \cdot$ Narihito Yoshioka $^{6} \cdot$ Naoko Tajima $^{7} \cdot$ Yoshimitsu Yamasaki $^{8}$
}

Published online: 21 September 2021

(c) The Author(s) 2021

\section{Correction to: Acta Diabetologica \\ https://doi.org/10.1007/s00592-021-01773-z}

Authors would like to correct the typo in author name of the last author. The author name is corrected from "Yamazaki" to "Yamasaki" in the original publication.

The original article has been corrected.
Open Access This article is licensed under a Creative Commons Attribution 4.0 International License, which permits use, sharing, adaptation, distribution and reproduction in any medium or format, as long as you give appropriate credit to the original author(s) and the source, provide a link to the Creative Commons licence, and indicate if changes were made. The images or other third party material in this article are included in the article's Creative Commons licence, unless indicated otherwise in a credit line to the material. If material is not included in the article's Creative Commons licence and your intended use is not permitted by statutory regulation or exceeds the permitted use, you will
The original article can be found online at https://doi.org/10.1007/ s00592-021-01773-Z.

Naoto Katakami

katakami@endmet.med.osaka-u.ac.jp

1 Department of Diabetes Care Medicine, Osaka University Graduate School of Medicine, 2-2 Yamadaoka, Suita City, Osaka 565-0871, Japan

2 Department of Metabolic Medicine, Osaka University Graduate School of Medicine, 2-2 Yamadaoka, Suita City, Osaka 565-0871, Japan

3 Department of Endocrinology, Tenri Hospital, 200 Mishimacho, Tenri City, Nara 632-8552, Japan
4 Department of Diabetes, Metabolism and Endocrinology, Jikei University School of Medicine, 3-25-8 Nishi-Shimbashi, Minato-ku, Tokyo 105-8461, Japan

5 Department of Endocrinology and Metabolism, Faculty of Medicine, University of Tsukuba, 1-1-1 Tennodai, Tsukuba City, Ibaraki 305-8575, Japan

6 NTT-East Sapporo Hospital, Minami 1 Jyo Nishi 15 Chome Chuo-Ku, Sapporo City, Hokkaido 060-0061, Japan

7 Otemachi Place Medical Clinic, 2-3-1, Otemachi, Chiyoda-ku, Tokyo 100-0004, Japan

8 Nishi-Umeda Clinic, 3-3-45 Umeda, Kita-ku, Osaka City, Osaka 530-0001, Japan 
need to obtain permission directly from the copyright holder. To view a copy of this licence, visit http://creativecommons.org/licenses/by/4.0/.
Publisher's Note Springer Nature remains neutral with regard to jurisdictional claims in published maps and institutional affiliations. 